\title{
Erratum to: Impact of Pregelatinized Starches on the Texture and Staling of Conventional and Degassed Pound Cake
}

\author{
Nesrin Hesso • Catherine Loisel • Sylvie Chevallier • \\ Alain Le-Bail
}

Published online: 11 April 2014

(C) Springer Science+Business Media New York 2014

\section{Erratum to: Food Bioprocess Technol}

DOI 10.1007/s11947-014-1254-5

The original version of the article unfortunately contains mistakes on Figure 4 and Figure 5 captions and hereby the authors have corrected these to state:

Fig. 4 Young's modulus (2-10\% strain) of microcakes as a function of storage period at $10 \pm 1{ }^{\circ} \mathrm{C}$. Experimental measures are fitted with Equation (2) for each cake, experimental values of the Young's modulus have to be multiplied by 100 .

Fig. 5 Young's modulus (5-18\% strain) of conventional cakes as a function of storage period at $10 \pm 1{ }^{\circ} \mathrm{C}$, experimental values of the Young's modulus have to be multiplied by 100 .

An error was also found at its imbedded text in the lower graph of Figure 7. The figure is hereby presented and corrected.

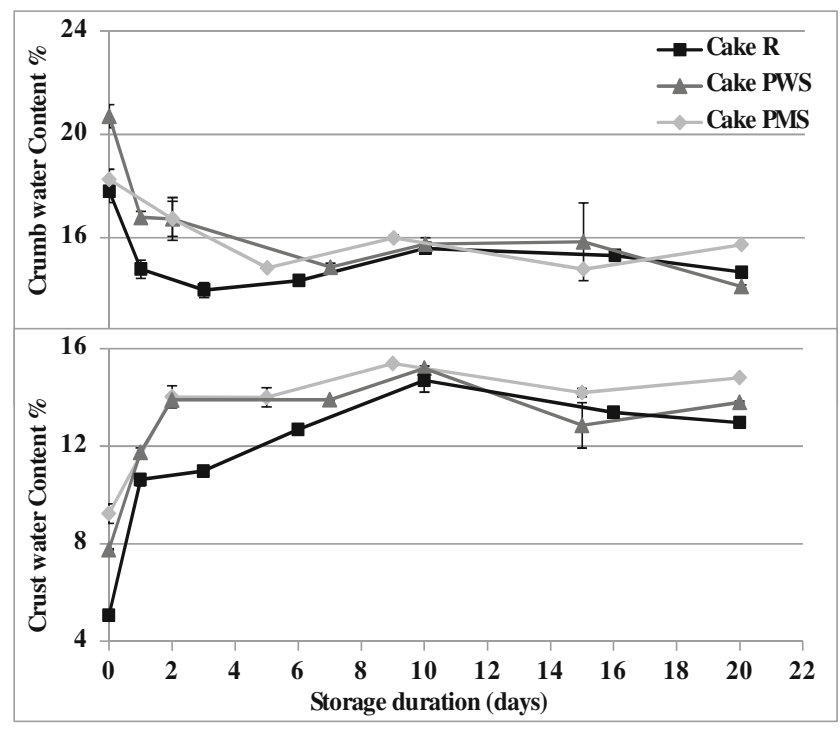

The online version of the original article can be found at http://dx.doi.org/ 10.1007/s11947-014-1254-5.

N. Hesso $\cdot$ C. Loisel $\cdot$ S. Chevallier $\cdot$ A. Le-Bail

ONIRIS, BP 82225, 44322 Nantes, France

N. Hesso $\cdot$ C. Loisel $(\bowtie) \cdot S$. Chevallier $\cdot$ A. Le-Bail

LUNAM Université Nantes Angers Le Mans,

UMR 6144 GEPEA CNRS, 44602 Saint-Nazaire, France

e-mail: catherine.loisel@oniris-nantes.fr 